\title{
PUNITIVISMO E O MITO DA INTRANSMISSIBILIDADE DA PENA
}

\author{
PUNITIVISM AND THE MYTH OF THE NON-TRANSFERABILITY OF \\ PENALTY
}

\author{
Gilberto Bramusse
}

RESUMO; O presente trabalho tem como tema central a inconstitucionalidade das revistas íntimas promovidas em grande parte das unidades prisionais do país. Para se pôr a análise deste tema, o trabalho se inicia com um panorama histórico acerca da relação espúria entre o capitalismo e o direito penal. $O$ trabalho se desenvolve com o relato de A.C.S. e E.C.A., no que diz respeito à forma como era realizado o processo de revista íntima para visitar seu familiar E.E.O., no presídio de Coronel Fabriciano-MG, de modo que os dados foram coletados a partir de pesquisa empírica. Por fim, foi feita uma breve análise de decisões judiciais acerca do tema.

Palavras-chave: Capitalismo. Família. Pena. Direito penal do autor.

ABSTRACT: This article has as its central theme the unconstitutionality of the intimate inspections promoted in almost all prison units in the country. In order to analyze this theme, the work begins with a historical overview of human dignity and the affirmation of human rights over time, highlighting the historical importance of the redemocratization of Brazil with the consequent affirmation of human rights in our country. The work is developed with the report of A.C.S. and E.C.A., regarding the way the intimate search process was carried out to visit their family member E.E.O., in the prison of Coronel Fabriciano-MG, so that the data were collected from empirical research. Finally, a brief analysis of judicial decisions on the subject was made.

Keywords: Capitalism. Family. Penalty. Criminal law of the author.

\section{INTRODUÇÃO}

Quando analisamos a conformação histórica do Direito Penal, que se desenvolveu no período de transição da baixa Idade Média, percebemos que a função de controle dos corpos e da manutenção da sociedade verticalizada é desempenhada por este ramo do Direito desde a sua instituição. Como bem lembram Rusche e Kirchheimer (2004), a pobreza extrema atrelada ao aumento da criminalidade foi um fator decisivo para que aqueles que detinham o poder buscassem outros meios mais efetivos de controle das grandes massas, encontrando na pena a dissuasão para os comportamento desviantes.

Segundo Rusche e Kirchheimer (2004), a maioria das condutas tipificadas naquele período eram práticas recorrentes dos membros das classes inferiores. Neste sentido, a palavra "vilão", que em sua etimologia refere-se àquele que é habitante de uma vila, começou 
a ser utilizada como um marcador social de uma pessoa delinquente, ou seja, a ideia de um inimigo a ser neutralizado estaria intimamente relacionada à classe social do sujeito.

Sendo assim, o capitalismo encontrou no Direito Penal, e na consequente pena privativa de liberdade, as condições ideais para o seu desenvolvimento. Como nos ensina Batista (1990), o capitalismo se recorre historicamente ao punitivismo estatal, sendo observado ver o surgimento das galés e das casas de trabalho. Portanto, percebe-se que o conteúdo da norma penal incriminadora se coaduna, desde os primórdios, com os valores do universo moral burguês.

Com o alavancar das revoluções liberais, direitos e garantias fundamentais foram positivados nos países centrais. Contudo, em relação às massas despossuídas e, sobretudo, no caso brasileiro, como um país escravagista de economia dependente, observa-se uma movimentação nas estruturas jurídicas não para se assegurar a isonomia jurídica, que é própria de um liberalismo coeso, mas para a manutenção do status quo por meio da coerção do direito, visando manter o controle das massas despossuídas, principalmente sobre os recém libertos, a partir de mecanismos de estigmatização e seleção prioritária para os sistemas de penais.

Dessa forma, cabe observar que o Código Penal Brasileiro de I89o tipificava, em seu artigo 399, a vadiagem, com o objetivo de garantir a mão de obra, já que estava sendo implementado o modelo de trabalho livre e, no Art. 206, criminalizava a greve, como forma de assegurar a manutenção do trabalho, além de proibir manifestações culturais atreladas aos escravizados, como o batuque. Logo, o sistema criminal assumia o controle sobre os corpos subalternos, já que com a urbanização houve um deslocamento dessas massas marginalizadas para as cidades, e o controle privado, que antes era exercido pelo senhor nos engenhos, passa às mãos do Estado. Neste contexto, destaca-se o seguinte: "Que não são embora sejam. Que não falam idiomas, falam dialetos. Que não praticam religiões, praticam superstições.(GALEANO, 1989, p. 42)"

Capítulo VI Da Polícia, Segurança, Tranqüilidade e Comodidade Pública Art. 63 São proibidos os batuques, danças e reunião de escravos na vila e povoação e seus subúrbios. Os moradores das casas onde eles se fizerem, ou os chefes das mesmas, reuniões, serão multados em ı\$ rs ou sofrerão ıo dias de cadeia. (CHARLES, 1988, p. 246)

Nesta tomada, no contexto brasileiro, o controle implementado pelas elites locais foi produto direto da transculturação dos sistemas punitivos dos países centrais, com ênfase na escola positivista, sobretudo a italiana de Garófalo, Lombroso e Ferri, que animalizava as populações não brancas, atribuindo como fatores decisivos para o comportamento desviante elementos biológicos, psicológicos e, segundo eles, o atavismo hereditário, próprio das raças tidas como inferiores. Segundo Zaffaroni (1991, p.77):

O verdadeiro modelo ideológico para o controle social periférico ou marginal não foi o de Bentham, mas o de Cesare Lombroso. Este modelo ideológico partia da premissa de inferioridade biológica tanto dos delinqüentes centrais como da totalidade das populações colonizadas, considerando, de modo análogo, biologicamente inferiores, tanto os moradores das instituições de seqüestro centrais (cárcere, manicômios), como os habitantes originários das imensas instituições de 
seqüestro coloniais (sociedades incorporadas ao processo de atualização histórica)." ( 1991, p. 77, apud CHARLES, 1988, p. 26)

Por conseguinte, o cárcere, que nasce com a finalidade de conter as massas marginalizadas e despossuídas, com o intuito de fornecer mão de obra para o chão da fábrica, é o ponto culminante do processo de estigmatização desempenhado pelo Direito Penal. ${ }^{1}$

\section{Direito enquanto reflexo dos axiomas das classes dominantes}

Como nos ensina Robert Merton (1938), o meio social funciona como uma força motriz para a inviabilização do acesso pleno a bens de consumo pelas parcelas sociais subalternas e o alcance da cultura que socialmente é introjetada (como o sucesso econômico). Entretanto, a reação social na busca por esses fins, por muitas vezes, é considerada como um comportamento desconforme. $\mathrm{Na}$ visão de Merton, seria uma inovação (corresponde à adesão aos fins culturais, sem o respeito aos meios institucionais). Neste sentido, a reação das instituições (Polícia, Ministério Público, Magistratura) seria taxar essa ação enquanto "patológica, perigosa e criminal” (BARATTA, 2oII).

Portanto, para o referido autor, o descompasso entre o fim culturalmente estabelecido como meta e os meios de que dispõe as castas inferiores para alcançar esses valores, estariam na base do comportamento desviante. Ou seja, a estrutura social não fornece a todos os estratos sociais os instrumentos necessários para a persecução e alcance desses valores introjetados pelo corpo social. Nesta tomada, Merton (1938) estabelece modelos de adequação individual.

I. Conformidade - corresponde à resposta positiva, tanto aos fins como aos meios institucionais e, portanto, ao típico comportamento conformista. Uma massa de indivíduos constitui uma sociedade somente se a conformidade é a atitude típica que nela se encontra.

2. Inovação - corresponde à aIdesão aos fins culturais, sem o respeito aos meios institucionais.

3. Ritualismo - corresponde ao respeito somente formal aos meios institucionais, sem a persecução dos fins culturais.

4. Apatia - corresponde a negação tanto dos fins culturais como dos meios institucionais.

5. Rebelião - corresponde, não à simples negação dos fins e dos meios institucionais, mas à afirmação substitutiva de fins alternativos, mediante meios alternativos (1938, p. 672. APUD BARATTA, 2011, p.64).

Segundo Merton (1938), a criminalidade tida como de colarinho branco, mais atrelada aos homens de negócio, funcionaria como um reforço desses axiomas dominantes, já que

\footnotetext{
${ }^{I}$ Desse modo, o processo de criminalização cumpriria função de conservação e de reprodução social: a punição de determinados comportamentos e sujeitos contribuiria para manter a escala social vertical e serviria de cobertura ideológica a comportamentos e sujeitos socialmente imunizados. O cárcere, finalmente, nascido da necessidade de disciplina da força de trabalho para consumo da fábrica, seria o momento culminante de processos de marginalização, discriminação e estigmatização, fechando um continum que abrange a família, escola e a assistência social. (Juarez Cirino. Prefácio, Criminologia Crítica e Crítica ao Direito Penal)
} 
delitos econômicos e ambientais, por exemplo, são escassamente perseguidos pelas instituições ou então nem são consideradas como condenáveis pelo senso comum.

A título de exemplificação, trazemos no corpo do texto o emblemático caso do Senador Chico Rodrigues flagrado com dinheiro nas nádegas (2020). Ao invés de punição pelo ato, o referido parlamentar se encontra entre os que mais receberam emendas no ano de 2020, segundo noticiado² pela BBC. Em contraponto, apresenta-se os autos $n^{\circ}$ 0396.12.1947-8 em que o acusado Flávio Júnio da Rocha, furtou quatro frascos de desodorantes, com o valor total de oito reias, e, segundo fundamenta o magistrado para a condenação, o réu apresentava personalidade distorcida e realizou o furto para aquisição de drogas. Apesar dos bens terem sido restituídos, Flávio Júnior da Rocha foi condenado "à pena de dois anos e dois meses de reclusão mais 30 dias-multa, à razão de $\mathrm{I} / 30$ avos do salário mínimo vigente à data do fato" (TJMG, Comarca de mantena - $\mathrm{I}^{\circ}$ vara, Sentença, o9 de outubro de 2013, autos 0396.12.1947-8)

Nesta tomada, diante do sujeito delinquente, o Estado se movimenta no sentido da defesa social, muito atrelada à visão maniqueísta entre o combate entre o bem e o mal, onde a sociedade seria a personificação do bom, perfeito e agradável, enquanto o delinquente corporificaria o mal a ser neutralizado.

Desta forma, o processo de criminalização se divide em duas fases. A primeira fase é a criminalização primária, que consiste na elaboração dos tipos penais pelo legislador. Neste diapasão, o Direito Penal é utilizado rotineiramente como um instrumento de reprodução de poder das classes dominantes que, pela atividade legiferante do Estado, criminaliza as condutas típicas das classes subalternas (como exemplificado nos parágrafos anteriores), a saber, crimes patrimoniais e pequenos delitos relacionados a drogas, enquanto os chamados crimes de colarinho branco entram para a cifra oculta do sistema punitivo estatal.

A segunda fase de criminalização diz respeito à atuação da polícia e do Ministério Público, bem como do Poder Judiciário no decurso da investigação à sentença do réu. Neste sentido, o indivíduo que já sofreu o processo de criminalização primária, agora terá sua conduta avaliada pelos órgãos estatais competentes.

Em uma nação que se rege por uma constituição democrática, participativa e permeada de direitos e garantias fundamentais soa, no mínimo, como uma aberração jurídica o fato de que, ao contrário de imparcial, o ordenamento jurídico seja, em suma, uma construção ideológica, reflexo dos axiomas e dogmas das classes dominantes. Cabe destacar que os dados do anuário de segurança pública do ano de 2020 revelam que houve, em 2019, 6.357 (seis mil trezentos e cinquenta e sete) mortes por intervenções policiais e, destas vítimas, 79,1\% eram negros, ressaltando que a atuação policial se insere no âmbito da criminalização secundária.

Diante disso, vemos a conformação de um Direito Penal subterrâneo, em que nem ao menos é dada ao "acusado" a chance de defesa em um processo penal dialético, permeado por direitos e garantias fundamentais. É aplicada apenas a pena capital, por um agente de segurança pública que se porta como um carrasco, aos moldes dos suplícios, narrados por Foucault. Portanto, é possível analisar e questionar os fundamentos históricos e valorativos que levaram à estruturação desses processos criminalizadores.

${ }^{2}$ Disponível em: 〈https://www.bbc.com/portuguese/brasil-5456r36r>Acesso, 26 de abril de 202I 
Adiante, o sistema prisional, como mencionado anteriormente, é o ápice da estigmatização desempenhada pelo direito penal, que serve desde a sua instituição aos interesses capitalistas e de controle das elites dominantes e opera como uma mecanismo de sequestro de corpos. Neste sentido, o Estado passa a desenvolver subsistemas para punir-se além da pena. Basta observar que o Supremo Tribunal Federal ao editar a súmula 439, reinsere no ordenamento jurídico a possibilidade de requisição de exames criminológicos 3 para fins de aferição de direitos à pessoa privada de liberdade - em que pese a nova redação dada ao Art. II2 da Lei de Execução Penal (1984), que aboliu os exames psicossociais. Ao proceder dessa forma, a Corte Superior ignora o fato de que o sistema prisional não desempenha suas funções declaradas, bem como o estado de coisas inconstitucionais que vive o sistema prisional no Brasil, vide ADPF 347. O referido exame se constitui em um exercício meramente futurista de tentativa de prever a possibilidade de reincidência do apenado, auferindo, por meio do comportamento carcerário e do convívio familiar, o grau de ressocialização da pessoa privada de liberdade. Assim, o sistema prisional, no desempenho de suas funções reais, desconstrói o interno enquanto pessoa, através, por exemplo, do discurso de ressocialização.

Desta forma, depositar as esperanças de "reeducação" do sujeito, tendo como instrumento a criminalização e a repressão estatal, mostra-se completamente inviável e paradoxal, haja vista ser a educação um instrumento de autoafirmação e emancipação da pessoa. O que, por outro lado, se opera no cárcere é a aplicação de uma disciplina rigorosa, de caráter repressivo e uniformizante, que revela um processo de dominação por meio da realização de cerimônias de degradação do sujeito.

\section{O mito da intransmissibilidade da pena}

A intransmissibilidade da pena está prevista no ordenamento pátrio desde a Constituição de I824. Contudo, vemos que o Estado brasileiro vem adotando o chamado Direito Penal do Inimigo em relação às famílias dos detentos, desconsiderando direitos e garantias tutelados na ordem interna e externa, como a intimidade, vedação ao tratamento desumano e degradante, valendo-se de mecanismos de intimidação, e submetendo aqueles que adentram nas unidades prisionais ao constrangimento de serem consideradas automaticamente suspeitas de portarem em seu corpo drogas, armas e dentre outros artefatos.

Fazendo uma análise da realidade vivenciada rotineiramente, sobretudo, por mulheres que possuem amigos ou familiares sob tutela estatal, percebemos um ritual de constrangimento que tem seu ápice no momento em que se vêm obrigadas a se despirem diante de autoridades policiais, efetuando agachamentos e assistindo, passivamente, seus corpos sendo violados. Diante desta situação humilhante e vexatória, notamos o completo desrespeito por parte do Estado ao princípio que o mesmo declarou como sendo seu fundamento: a dignidade humana.

\footnotetext{
3 "Dada a complexidade do conceito de personalidade, torna-se inviável ao juízo da execução produzir uma avaliação dinâmica e, sobretudo, pacífica da personalidade do condenado. Trata-se de conceito fluido, que não autoriza um juízo de certeza necessário à segurança jurídica." (ROIG, 20I8, p. 7).
} 
A seguir serão descritos dois relatos de pessoas que visitaram um familiar no presídio. Para preservar a identidade dos envolvidos, os nomes não serão revelados, utilizando apenas as iniciais do nome para identificação.

Quanto aos relatos de A.C.S e E.C.A. ao visitarem seu familiar no presídio de Coronel Fabriciano/MG, expõem que os dias de visitação aos presos com sentença final condenatória ocorria aos sábados tendo início às o8:0o e se estendendo até às i6:0o horas, não sendo incomum que visitantes, em sua maioria mulheres, dormissem na fila. Relatam ainda que, para que a visita pudesse ocorrer, era necessário realizar o cadastramento na unidade prisional, com o prévio consentimento do preso à ser visitado. $O$ procedimento adotado pela unidade supracitada se dividia basicamente em três etapas. Na primeira etapa, os pertences, tais quais artigos de higiene pessoal, a chamada "barriguda" (artigos como biscoitos, doce de leite, suco em pó) e o almoço passam pelo raio-x e o visitante pelo detector de metais. Desta sorte, o indivíduo era conduzido à segunda etapa, no qual ocorria a censura dos itens de higiene pessoal, bem como os artigos alimentícios. A terceira e última etapa, objeto de questionamento deste artigo, consiste na revista íntima do visitante, não importando sua idade ou condição física. Neste procedimento, o indivíduo se despia totalmente ante ao policial penal, enquanto o mesmo verificava a existência de possíveis artefatos escondidos nas roupas, feito isso, o revistado era obrigado a efetuar em média seis agachamentos e ter seus cabelos revirados, dentre outras medidas. Não era incomum relatos de mulheres ao serem revistadas, serem obrigadas a se colocarem em posições humilhantes como colocar uma das pernas na parede ou até mesmo "ficar de quatro" para que a agente pudesse verificar a existência ou não de objetos ilícitos em sua vagina.

Outra situação de completo constrangimento e humilhação, conforme relataram, foi a de uma visitante, com notória debilidade motora, ser impedida de adentrar na unidade com sua cadeira de rodas sendo necessário que seus familiares a carregassem até o pátio, local onde se daria a visita. A interferência Estatal era tão intensa que haviam restrições quanto às cores das roupas que poderiam trajar durante o tempo que estivessem na unidade prisional.

A convenção contra a tortura e outros tratamentos ou penas cruéis, desumanos ou degradantes , adotada pelas Nações Unidas (1984), surge com o intuito de inibir práticas que outrora foram aplicadas em contextos históricos de flagrantes violações a dignidade da pessoa humana como na Segunda Guerra e nos governos autoritários. Nota-se, por esta convenção, que tortura não é apenas o sofrimento físico, mas também o psíquico. Com base nisso, cabe a importância de se pensar as diversas esferas de sofrimentos criados pelo Estado, sendo um deles a revista vexatória a que amigos e familiares de detentos são submetidos. Segundo a Professora Cristina Rauter ${ }^{4}$, o procedimento tem efeitos tão nefastos àqueles que se submetem ao mesmo, que desencadeiam sequelas psicológicas que se aproximam em muito a dos torturados pelo regime militar. Ainda, segundo o relator especial da ONU Juan E. Méndez, a prática da revista íntima constitui flagrante violação, sendo caracterizada como cruel, desumana e que viola a integridade sexual dos visitantes.

Feito desta forma, o procedimento funciona como uma extensão da pena e uma forma de punição aos visitantes. "A revista vexatória é, simultaneamente, grave violação à

\footnotetext{
4 É professora titular de Psicologia Social e Institucional do Departamento de Psicologia da Universidade Federal Fluminense, onde atua na graduação e na pós-graduação.
} 
individualização da pena e atentado à dignidade da pessoa humana do visitante. E, por isso, nunca deveria ter existido" (CALMON, G. 2014). Neste sentido, nos defrontamos com flagrante violação da Convenção Americana Sobre Direitos Humanos (1969), que estatui em seu Art. $5^{\circ}$ que " toda pessoa tem o direito de que se respeite sua integridade física, psíquica e moral; A pena não pode passar da pessoa do delinquente.”

Quando encaramos o principal motivo para se manter o procedimento, vemos a inconsistência do argumento utilizado pelo Estado. Observamos que, em uma pesquisa de 2012, feita apenas no estado de São Paulo, percebeu-se que em cerca das 3,5 milhões de revistas realizadas apenas $0,02 \%$ dos visitantes foram flagrados com artefatos ilícitos 5 , ou seja, drogas, explosivos, dentre outros. Sendo assim, é possível pensar que tais objetos adentram no sistema prisional não por meio dos visitantes, mas por outras vias. Por esta razão, a entidade não governamental Conectas denunciou tal prática à OEA.

Neste sentido, se põe em clarividência que a prática de tal ato além de violar princípios resguardados em sede constitucional, como a intimidade e a dignidade humana, também afrontam regras internacionais, por violarem a proporcionalidade, haja vista, não ser um método necessário nem eficiente. Neste sentido, apresenta-se no corpo deste trabalho, parte do relatório elaborado pelo Subcomitê de prevenção à tortura entregue ao governo brasileiro no ano de 2012:

O SPT recomenda que o Estado garanta que as revistas cumpram com os critérios de necessidade, razoabilidade e proporcionalidade. Se conduzidas, as revistas corporais devem ser realizadas em condições sanitárias adequadas; por pessoal qualificado, do mesmo sexo do indivíduo revistado; e devem ser compatíveis com a dignidade humana e com o respeito aos direitos fundamentais. Revistas intrusivas, como vaginais e anais, devem ser proibidas por lei 42. A emissão de passes para os visitantes deve ser agilizada. (Relatório Subcomitê de Prevenção da Tortura, 2012)

Por conseguinte, a definição de tortura, estabelecida pelo texto da Convenção contra a Tortura e Outros Tratamentos ou Penas Cruéis, encontra-se em seu artigo primeiro, cabendo salientar que o Brasil é signatário desde o ano de 1989 do referido tratado. Para os fins da presente Convenção, o termo "tortura" designa qualquer ato pelo
qual dores ou sofrimentos agudos, físicos ou mentais, são infligidos
intencionalmente a uma pessoa a fim de obter, dela ou de uma terceira pessoa,
informações ou confissões; de castigá-la por ato que ela ou uma terceira pessoa
tenha cometido ou seja suspeita de ter cometido; de intimidar ou coagir esta pessoa
ou outras pessoas; ou por qualquer motivo baseado em discriminação de qualquer
natureza; quando tais dores ou sofrimentos são infligidos por um funcionário
público ou outra pessoa no exercício de funções públicas, ou por sua instigação, ou
com o seu consentimento ou aquiescência. Não se considerará como tortura as
dores ou sofrimentos que sejam consequência unicamente de sanções legítimas, ou
que sejam inerentes a tais sanções ou delas decorram. (Convenção contra a Tortura
e Outros Tratamentos ou Penas Cruéis, art. $\mathrm{I}^{\circ}$, 1989)

\footnotetext{
5 Dados obtidos através de estudo do informativo rede justiça criminal, disponível em <https://redejusticacriminal.org/wp-content/uploads/2016/o8/Revista-Vexat\% $\mathrm{C}_{3} \% \mathrm{~B}_{3}$ ria-Pesquisa-analisee-entrevista-sobre-o-tema.pdf $>$
} 
Neste diapasão, o ordenamento jurídico brasileiro admite a possibilidade de revista íntima sem a necessidade de autorização judicial, porém como requisito mínimo estabelece a fundada suspeita que o indivíduo traga consigo objetos ilícitos, como dispõe o Art. 244 do Código de Processo Penal ${ }^{6}$. Segundo a nona resolução ${ }^{7}$ do Conselho Nacional de Política Criminal e Penitenciária, a revista só deveria ser efetuada com base em fundada suspeita e mediante critérios objetivos. Contudo, o que se observa na realidade carcerária brasileira é o constrangimento de todos os visitantes a passarem pelo procedimento, como sendo potencialmente transgressores da norma penal incriminadora.

Fica evidente a conformação de um Direito Penal do Autor, que vê no indivíduo vítima da persecução penal e em seus familiares entes daninhos ao convívio social que, portanto, devem ser neutralizados pelo braço repressor do Estado.

Como possíveis alternativas ao poder estatal de punir há algumas correntes. Dentre estas, aparece o abolicionismo penal, que defende a superação completa do poder punitivo do Estado, tendo em vista todas as suas distorções e contradições. A completa extinção do poder punitivo do Estado traz consigo uma visão socialmente interessada nas consequências negativas da pena para o indivíduo, como o efeito estigmatizante e as funções reais que a privação de liberdade e os processos de criminalização desempenham na pessoa e em seus familiares. Além disso, é um paradoxo que a pessoa presa aprenda a viver em liberdade, tendo sido afastada do convívio social e familiar.

\footnotetext{
6 A busca pessoal independerá de mandado, no caso de prisão ou quando houver fundada suspeita de que a pessoa esteja na posse de arma proibida ou de objetos ou papéis que constituam corpo de delito, ou quando a medida for determinada no curso de busca domiciliar.

7 “A revista manual só se efetuará em caráter excepcional, ou seja, quando houver fundada suspeita de que o revistando é portador de objeto ou substância proibidos e/ou que venha a pôr em risco a segurança do estabelecimento.

Parágrafo único. A fundada suspeita deverá ter caráter objetivo, diante de fato identificado e de reconhecida procedência, registrado pela administração, em livro próprio e assinado pelo revistado" (ART. $2^{\circ}$ Resolução $n^{\circ}$ 9, CNPCP, 2006)

“Art. $4^{\underline{0}}$ - O procedimento padronizado de revista, previsto no art. 2º , não inclui a realização de revista íntima, que será efetuada excepcionalmente, dentro dos limites fixados nesta Lei.

$\S$ Io- Considera-se revista íntima toda e qualquer inspeção das cavidades corporais vaginal e anal, das nádegas e dos seios, efetuado visual ou manualmente, com auxílio de instrumento ou objeto, ou de qualquer outra maneira.
}

$\S 2^{\mathrm{O}}$ - A revista íntima será realizada exclusivamente com expressa autorização do Diretor do estabelecimento prisional, baseada em grave suspeita ou em fato objetivo específico que indique que determinado visitante pretende conduzir ou já conduz algum tipo de arma ou droga em cavidade do corpo.

$\S 3^{\mathrm{O}}$ - Previamente à realização da revista íntima, o Diretor do estabelecimento fornecerá ao visitante declaração escrita sobre os motivos e fatos objetivos que justifiquem o procedimento.

$\S 4^{\mathrm{O}}$ - Quando não houver tempo suficiente para sua expedição prévia, o documento a que se refere o $\S 3^{\circ}$ será fornecido até 24 (vinte e quatro) horas depois da revista íntima, sob pena de sanção administrativa.

$\S 5^{\circ}$ - A revista íntima será efetuada de forma a garantir a privacidade do visitante, por pessoa do mesmo sexo, com formação na área de saúde." 
Portanto, quando o legislador tipifica uma conduta, deve se abster de uma moral majoritária, de proteger bens jurídicos demasiadamente abstratos - como legitimar a persecução penal em casos de tráfico de drogas, a fim de tutelar a saúde pública. Fica, por muitas vezes, evidente que o Direito Penal funciona como um mecanismo de controle social e como uma forma de retirar de circulação aqueles corpos indesejáveis, selecionando as classes inferiores e suas condutas para o processo de criminalização.

Outra afronta à Constituição diz respeito à violação das cartas que familiares enviam aos presos por parte dos agentes prisionais, sendo o envelope aberto e só posteriormente entregue aos detentos, tudo isto em nome de coibir possíveis ameaças a terceiros. Esta conduta não se justifica, haja vista, a inviolabilidade das correspondências, e que, em outras situações os detentos estabelecem diálogos com terceiros, sendo vedada a presença de agentes públicos, como em conversas com advogados e em visitas íntimas.

Por conseguinte, as posições adotadas pelos Tribunais têm sido no sentido de coibir que tais violações continuem a acontecer, conforme decisão tomada em Campinas (2017), onde se entendeu ser o procedimento incompatível com princípios constitucionais por violar a honra, imagem e a intimidade dos visitantes. Em resposta à ação civil pública proposta pela Defensoria Pública do estado de São Paulo, a $4^{-2}$ Região Administrativa Judiciária entendeu que a revista vexatória não se justifica, haja vista, a existência de tecnologias que impedem que artefatos ilícitos adentrem no sistema prisional, no mesmo passo que garantem um tratamento mais humanizado aos visitantes. O estado de São Paulo foi condenado a pagar a importância de trezentos e cinquenta mil reais ao Fundo Estadual de Defesa dos Interesses Difusos.

Tramita no Supremo Tribunal Federal um caso de origem do Rio Grande do Sul, em que uma mulher ao visitar seu irmão no presídio de Porto Alegre adentrou na unidade com 96 gramas de maconha em sua vagina. Com o transcurso do processo, entendeu o Tribunal de Justiça daquele estado que se tratava de uma prova ilícita, uma vez que foi colhida por via de revista vexatória em flagrante violação de direitos assegurados constitucionalmente. Em decorrência disto, houve a absolvição da ré.

Outra importante decisão no plano internacional foi a condenação do Estado Argentino pela violação sofrida por uma mulher e sua filha ao serem submetidas a revista íntima em um presídio federal do país. Na decisão, a Comissão de Direitos Humanos da OEA entendeu que as autoridades Federais, ao realizarem inspeções vaginais, violaram direitos assegurados pela Convenção Americana sobre Direitos Humanos, e entendeu ser mister que os critérios que levam a averiguação íntima devem ser objetivos, e não subjetivos e irrestritos. Conforme decisão proferida sobre o caso 10.506 no ano de 1996 , julgado pela Comissão de Direitos Humanos da OEA.

\section{CONCLUSÃO}

Diante de tudo isto, fica evidente que a revista íntima descumpre os critérios da proporcionalidade não se mostrando adequada, pois a medida não promove o fim desejado, bastando observar os índices de objetos apreendidos durante as inspeções, em relação ao número de revistas realizadas e a permanência do problema de drogas e armas nas unidades prisionais. Assim, tal medida se mostra pouco necessária, pois há outras alternativas que promovem em maior grau os direitos fundamentais levando em conta a existência de tecnologias, como, por exemplo, o scanner corporal. 
Diante dos graves constrangimentos sofridos por milhares de pessoas ao visitarem seus familiares ou amigos internados em unidades prisionais, somando ao que dispõe o ordenamento nacional e nos tratados internacionais, entende-se ser este procedimento degradante e constituindo tortura psicológica, de modo que não se justifica sua manutenção.

\section{REFERÊNCIAS}

ASSEMBLÉIA GERAL DAS NAÇÕES UNIDAS. Convenção Contra a Tortura e Outros Tratamentos ou Penas Cruéis, Desusmanos ou Degradantes, dez. de 1984.

BARATA, Alessandro. Criminologia Crítica e Crítica ao Direito Penal. Rio de Janeiro, 2orr.

BATISTA, Nilo. Punidos e Mal Pagos: Violência, Justiça, Segurança Pública e Direitos Humanos no Brasil de hoje. Rio de Janeiro: Revan Ltda., 1990.

BRASIL. ARGUIÇÃO DE DESCUMPRIMENTO DE PRECEITO FUNDAMENTAL no 347 , de 26 de abril de 2015. Providências para crise prisional. [S. 1.].

BRASIL. Código Penal de 1890 no № 847 , out. de 1890.

BRASIL. Constituição de 1824, mar. de 1824. Constituição Política do Império do Brasil, elaborada por um Conselho de Estado e outorgada pelo Imperador D. Pedro I.

BRASIL. Lei no 3.689, de 3 de outubro de 194r. Código de Processo Penal. Disponível em: http://www.planalto.gov.br/ccivil_o3/decreto-lei/del3689compilado.htm. Acesso em: 28 dez. 2020.

BRASIL. Lei no 7.210, de Ir de julho de 1984. Institui a Lei de Execução Penal. Diário Oficial da União, [S. l.], 13 jul. 1984 .

CONSELHO NACIONAL DE POLÍTICA CRIMINAL E PENIENCIÁRIA. Resolução $\mathbf{n}^{\circ} \mathbf{N}^{\circ} \mathbf{9}$, de $\mathbf{1 2}$ de julho de 2006. Recomenda a adoção de procedimentos quanto à revista nos visitantes, servidores ou prestadores de serviços e/ou nos presos, e dá providências. [S. l.], 27 abr. 2021.

CONVENÇÃO AMERICANA SOBRE DIREITOS HUMANOS, nov. de 1969. AMERICAN CONVENÇÃO ON HUMAN DIREITOS. [S. l.], 28 abr. 2021. Disponível em: https://www.cidh.oas.org/basicos/portugues/c.convencao_americana.htm. Acesso em: 13 abr. 2021.

FÓRUM BRASILEIRO DE SEGURANÇA PÚBLICA. Anuário Brasileiro de Segurança Pública 2020. Fórum Brasileiro de Segurança Pública. $[S$. l.], 19 out. 2020. Disponível em: https://forumseguranca.org.br/anuario-brasileiro-seguranca-publica/. Acesso em: 04/202I.

GALEANO, Eduardo. Os ninguéns. In: O LIVRO dos abraços. [S. 1.: s. n.], 1989.

MAGENTA, André. Pego com dinheiro nas nádegas, Chico Rodrigues está no 'top ro' de senadores com mais emendas liberadas em 2020. BBC, $[S$. l.], p. 545454, is out. 2020. Disponível em: https://www.bbc.com/portuguese/brasil-5456r36r. Acesso em: 26 abr. 2021.

MARIATH, Carlos. Limites da revista corporal no âmbito do sistema penitenciário. Jus Navigandi, [S. l.], abr. 2008. Disponível em: https://jus.com.br/artigos/Ir205/limites-da-revista-corporal-no-ambito-do-sistemapenitenciario\#: : :text=REVISTA\%20CORPORAL\%20NO\%20\%C $3 \% 82$ MBITO\%20PENITENCI\%C $3 \% 8$ IRI

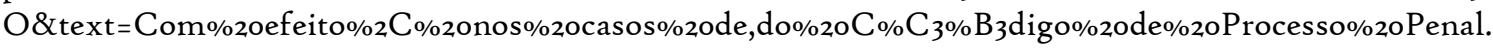

Acesso em: 26 fev. 202r.

MARTINS , Helena. Avança na Câmara projeto que acaba com a revista íntima em presídios: A prática é chamada de revista vexatória por constranger os visitantes. Brasília: Agência Brasil, 20 maio 2018. Disponível 
em: https://agenciabrasil.ebc.com.br/direitos-humanos/noticia/20r8-o5/avanca-na-camara-projeto-queacaba-com-revista-intima-em-presidios. Acesso em: 3 fev. 202I.

MINAS GERAIS. Tribunal de Justiça do Estado de Minas Gerais (Comarca de Mantena - $1^{\circ}$ Vara). Sentença pela prática do crime tipificado no artigo 155, caput, do Código Penal. Autos n 0396.12.1947-8. Autor: Ministério Público do Estado de Minas Gerais. Acusado: Flávio Júnior da Rocha.

NOTÍCIAS Supremo Tribunal Federal. In: Plenário decidirá se revista íntima para ingresso de visitantes em presídio viola princípios constitucionais. $[S . \quad$ l. $]$, I jun. 2018. Disponível em: http://www.stf.jus.br/portal/cms/verNoticiaDetalhe.asp?idConteudo=38orio. Acesso em: 30 dez. 2020.

NOVE estados já proibiram a revista pessoal vexatória em unidades prisionais: A revista vexatória, grave violação à individualização da pena e atentado à dignidade da pessoa humana do visitante. JusBrasil, fev. 2014. Disponível em: https://sergiooliveiradesouza.jusbrasil.com.br/artigos/139575531/nove-estados-ja-proibirama-revista-pessoal-vexatoria-em-unidades-prisionais. Acesso em: 20 abr. 2021.

PIOVESAN, Flávia. Direitos humanos e o direito constitucional internacional. São Paulo: Saraiva, 2013.

ORGANIZAÇÃO dos Estados Americanos: RELATÓRIO ANUAL 1996. In: RELATÓRIO № 38/96 : CASO I0.506 ARGENTINA. [S. l. $]$ is out. 1996. Disponível em: https://cidh.oas.org/annualrep/96port/Casoriso6.htm. Acesso em: 6 out. 2020.

Relatório sobre a visita ao Brasil do Subcomitê de Prevenção da Tortura e outros Tratamentos ou Penas Cruéis, Desumanos ou Degradantes. Ministério Público Federal, [S. l.], fev. 2orz. Disponível em: https://midia.mpf.mp.br/pfdc/hotsites/sistema_protecao_direitos_humanos/docs/sistema-nacoesunidas/orgaos-monit. Acesso em: 6 abr. 2021

Rauter, C. A “revista vexatória" e sua "utilidade" inconfessável no sistema penal brasileiro. Brandão, E. P. (org). In: Atualidades em Psicologia Jurídica. Rio: Nau, 2016, pp. 221-238.

ROIG, Rodrigo. Execução pena: Execução penal. 4. ed. São Paulo: Saraiva Educação, 2018.

RUSCHE, Georg; KIRCHHEIMER, Otoo. Punição e Estrutura Social. Rio de Janeiro: Revan Ltda., 2004.

SCHINDLER, Leila. A revista íntima violentando a dignidade da pessoa humana: mudanças estão por vir. Âmbito Jurídico, [S. l.] I ago. 2016. Disponível em: https://ambitojuridico.com.br/cadernos/direito-penal/arevista-intima-violentando-a-dignidade-da-pessoa-humana-mudancas-estao-por-vir/. Acesso em: 17 mar. 2021.

SANTOS, Juarez. Prefácio. In: BARATA, Alessandro. Criminologia Crítica e Crítica ao Direito Penal. [S. l.: s. n.], 02/10/2011.

SILVA, José; PIMENTA, Victor; LOUREIRO, João; NUNES, Ana; DAUFEMBACK, Valdirene; COSTA, Lucio. Relatório Anual 2017. Mecanismo Nacional de Prevenção e Combate à Tortura, maio 2018. Disponível em: https://www.gov.br/mdh/pt-br/assuntos/noticias/2018/julho/mdh-recebe-relatorio-de-atividades-domecanismo-nacional-de-prevencao-e-combate-a-tortura/RelatrioAnual2or7MNPCT.pdf. Acesso em: i abr. 2021. 
Revista Ibero- Americana de Humanidades, Ciências e Educação- REASE

${ }_{\text {oPEN }}{ }_{\text {ACCESS }}$ 